\title{
Handout Matematika berbantuan Etnomatematika Berbasis Budaya Lokal
}

\author{
Elma Purnama Aini ${ }^{1 *}$, Komarudin ${ }^{1}$,Ruhban Masykur ${ }^{1}$ \\ ${ }_{1}^{1}$ Universitas Islam Negeri Lampung. Alamat: jalan Let. Kol. H. Endro Suratmin Sukarame I, \\ Bandar Lampung, Indonesia. \\ *Corresponding Author. E-mail: elmaaini@yahoo.com
}

Received : 30-11-2017; Revised : 24-01-2018; Accepted : 29-01-2018

\begin{abstract}
Abstrak
Penelitian ini bertujuan untuk mengembangkan bahan ajar berupa handout melalui pendekatan etnomatematika berbasis budaya lokal pada materi bangun datar. Model penelitian yang digunakan adalah penelitian pengembangan Borg and Gall, Namun pada penelitian ini hanya dibatasi sampai tujuh langkah penelitian dan pengembangan, yaitu: 1) Potensi dan Masalah; 2) Mengumpulkan informasi; 3) Desain Produk; 4) Validasi Desain; 5) Revisi Desain; 6) Uji Coba Produk; dan 7) Revisi Tahap Ahir. Teknik pengumpulan data yang digunakan dalam penelitian ini, yaitu wawancara, observasi, dan kuesioner (angket). Teknik analisis data menggunakan analisis deskriptif kualitatif yang memaparkan hasil pengembangan produk. Berdasarkan hasil analisis data ditinjau dari aspek kualitas kevalidan bahan ajar memperoleh skor rata-rata 3,97 dengan kategori "Valid". Sedangkan respon peserta didik pada uji coba terbatas memperoleh nilai rata-rata 3,67 dengan kategori "Praktis", dan angket respon peserta didik pada uji coba luas memperoleh nilai rata-rata 4,02 dengan kategori "Menarik". Hal ini dapat disimpulkan bahwa bahan ajar yang dikembangkan mempunyai kriteria valid, praktis, dan menarik sehingga dapat digunakan sebagai bahan ajar dalam kegiatan belajar mengajar.
\end{abstract}

Kata kunci : Budaya Lokal; Etnomatematika; Handout.

\begin{abstract}
This study aims to develop teaching materials in the form of handouts through a local culturebased ethnomathematics approach to the wake-up material. The research model used is the research of Borg and Gall development, but in this study only limited to seven steps of research and development, namely: 1) Potential and Problems; 2) Gathering information; 3) Product Design; 4) Design Validation; 5) Design Revisions; 6) Product Trial; and 7) Revision of the Ahir Phase. Data collection techniques used in this study, namely interviews, observation, and questionnaires (questionnaires). Data analysis techniques using descriptive qualitative analysis that describes the results of product development. Based on the result of data analysis, it is evaluated from the quality aspect of the prevalence of teaching materials to get the average score of 3.97 with the category of "Valid". While the learner's response to a limited trial earned an average grade of 3.67 with the "Practical" category, and the questionnaire response of learners on a large trial earned an average of 4.02 under the "Pull" category. It can be concluded that the developed teaching materials have valid, practical, and interesting criteria that can be used as teaching materials in teaching and learning activities.
\end{abstract}

Keywords: Handout; Ethnomatics; Local Culture.

\section{PENDAHULUAN}

\begin{tabular}{lcr}
\multicolumn{1}{c}{ Pada } & era kemajuan ilmu \\
pengetahuan & teknologi, tentunya \\
pendidikan & harus & mengikuti \\
perkembangan & zaman yang ada, karena \\
pendidikan merupakan sarana untuk
\end{tabular}

menuju kepada pertumbuhan dan perkembangan bangsa. Pendidikan juga merupakan investasi sumber daya manusia jangka panjang yang mempunyai nilai strategis bagi kelangsungan peradaban manusia di dunia (Rahmayani, 
Hindun, \& Hudha, 2015). Maka dari itu, pendidikan menjadi salah satu modal penting untuk memajukan sebuah bangsa karena kesejahteraan dan kemajuan sebuah bangsa dapat dilihat dari tingkat pendidikannya. Pendidikan memegang peranan penting dalam menciptakan individu berkualitas (Widyawati, 2016). Maka dari itu sudah seharusnya sudah ada inovasi-inovasi dalam dunia pendidikan sebagai jembatan untuk mengembangkan kreatifitas siswa. Salah satu pendidikan yang dapat mengembangkan kemampuan serta kreatifitas adalah pendidikan matematika yang berarti didalamnya terdapat pelajaran matematika (Anggoro, 2016; Cahyono, 2017).

Matematika terstruktur dalam proses pembelajarannya, terorganisasi dan berjenjang yang artinya terdapat hubungan antara materi satu dengan yang lainnya. Dalam pembelajaran matematika, hal yang sangat penting diselesaikan adalah dalam pemecahan masalah itu sebagai jantungnya matematika (Putra, 2016; Widyastuti, 2015). Padahal dalam mempelajari matematika tidak hanya sekedar memahami konsep atau prosedur, akan tetapi banyak hal yang dapat muncul dari hasil proses pembelajaran matematika. Namun pada kenyataannya masih banyak hasil belajar siswa masih berada dibawah nilai kkm (Irwandani \& Juariyah, 2016; Syaban, 2008).

Penelitian terkait sebelumnya mengemukakan bahwa handout berpengaruh untuk melengkapi proses pembelajaran(Nelson-Wong \& Callaghan, 2014). Farnaz Zahedi Avval dkk, juga mengemukakan bahwa handout menciptakan lingkungan pembelajaran yang lebih efekif (Avval, Jarahi, Ghazvini, \& Youssefi, 2013). Penelitian ini akan mengembangkan handout menggunakan pendekatan Etnomatematika.

Ethnomathematics mencakup ideide matematika, pemikiran dan praktik yang dikembangkan oleh semua budaya (Astri, Aji, Tias, \& Budiman, 2013). Selama dua atau tiga dekade terakhir, berbagai politik, budaya, dan pendidikan telah membawa etnomatika dan multikulturalisme pada umumnya meluas. Penting untuk menggunakan etnomatika dalam pengajaran metodologi dan khususnya program Pendidikan (Wahyuni, Tias, \& Sani, 2013). Penelitian lain mengatakan bahwa di kebudayaan Hausa permainan tradisional anak-anak menggunakan ilmu matematika diantaranya, aljabar, koordinat geometri, deret aritmatika, dan deret geometri.

Berdasarkan hal ini penulis melakukan sebuah penelitian dengan judul pengembangan handout melaui Pendekatan etnomatematika berbasis budaya lokal pada pembelajaran matematika. Kebaruan dalam penelitan ini dengan Penelitian ini menggunakan menggunakan pendekatan etnomatematika.

\section{METODE}

Jenis penelitian ini adalah penelitian dan pengembangan $(R \& D)$. Penelitian dan pengembangan ini menggunakan metode dari Borg and Gall yang telah dimodifikasi oleh Sugiyono menjadi 10 tahapan. Dikarenakan keterbatasan peneliti dalam penelitian ini baik dari segi waktu, kemampuan maupun dari segi biaya maka penelitian ini dibatasi hanya sampai 7 tahap yaitu :

1. Potensi dan masalah

2. Mengumpulkan imformasi

3. Desain produk

4. Validasi desain

5. Perbaikan produk

6. Uji coba terbatas dan ujicoba luas

7. Revisi produk

Dalam pengumpulan data, terdapat 2 teknik yang digunakan peneliti yaitu wawancara dan angket skala likert dengan 5 jawaban. Penskoran yang 
Desimal, 1 (1), 2018 - 75

Elma Purnama Aini, Komarudin, Ruhban Masykur

digunakan dalam penilaian validasi ahli dapat dilihat pada Table 1.

Tabel. 1 Penskoran analisis instrumen

\begin{tabular}{rlc}
\multicolumn{3}{c}{ validasi } \\
\hline No & \multicolumn{1}{c}{ Pilihan Jawaban } & Skor \\
1 & Sangat Setuju (SS) & 5 \\
2 & Setuju (S) & 4 \\
3 & Netral (N) & 3 \\
4 & Tidak Setuju (TS) & 2 \\
5 & Sangat Tidak Setuju (STS) & 1 \\
\hline
\end{tabular}

Rumus menghitung skor total tiap validator untuk setiap aspek dengan rumus:

$\bar{V}=\frac{\sum_{i=1}^{n} x_{i}}{n}$

Keterangan:

$\bar{V}=$ Rata-rata total validitas

$x_{i}=$ Skor aspek ke- $i$

$x_{i}=$ Banyaknya aspek

Dan rumus menghitung rata-rata tiap aspek dari semua validator:

$\bar{x}=\frac{\sum_{i=1}^{n} \bar{V}}{n}$

Keterangan:

$\bar{x}=$ Rata-rata total semua validator

$\bar{V}=$ Rata-rata validasi validator

$\mathrm{n}$ = Banyaknya validator

Hasil yang diperoleh diintepretasikan dengan menggunakan Tabel. 2:

Tabel. 2 Kriteria Pengkategorian Validitas

\begin{tabular}{cc}
\hline Interval Skor & Kategori \\
$0 \leq \bar{x}<1,8$ & Tidak valid \\
$1.8 \leq \bar{x}<2,6$ & Kurang valid \\
$2,6 \leq \bar{x}<3,4$ & Cukup valid \\
$3,4 \leq \bar{x}<4,2$ & Valid \\
$4,2 \leq \bar{x} \leq 5$ & Sangat valid \\
\hline
\end{tabular}

Tabel 3. Penskoran pada angket uji kepraktisan untuk setiap pernyataan

\begin{tabular}{clcc}
\hline No & \multicolumn{1}{|c}{ Pilihan jawaban } & $\begin{array}{c}\text { Skor } \\
\text { (+) }\end{array}$ & $\begin{array}{c}\text { Skor } \\
(-)\end{array}$ \\
1 & Sangat Setuju & 1 & 5 \\
2 & Setuju & 2 & 4 \\
3 & Netral (N) & 3 & 3 \\
4 & Tidak Setuju (TS) & 4 & 2 \\
5 & Sangat Tidak Setuju & 5 & 1 \\
\hline
\end{tabular}

Rumus menghitung persentase kepraktisan dan kemenarikan dengan rumus :

$\bar{P}=\frac{\sum_{i=1}^{n} \bar{P}_{i}}{n}$

Keterangan:

$\bar{P}=$ Skor rata-rata kepraktisan

$\bar{P}_{i}=$ Skor rata-rata kepraktisan peserta didik ke-i

$n$ = Banyaknya peserta didik

Selanjutnya rata-rata yang didapat dibandingkan dengan kriteria pengkategorian kepraktisan handout.

Hasil yang diperoleh diintepretasikan dengan menggunakan Tabel 4

Tabel. 4 Kriteria Pengkategorian Kepraktisan

\begin{tabular}{cc} 
Interval Skor & Kategori \\
$0 \leq \bar{x}<1,8$ & Tidak praktis \\
$1.8 \leq \bar{x}<2,6$ & Kurang praktis \\
$2,6 \leq \bar{x}<3,4$ & Cukup praktis \\
$3,4 \leq \bar{x}<4,2$ & Praktis \\
$4,2 \leq \bar{x} \leq 5$ & Sangat praktis \\
\hline
\end{tabular}

Sedangkan penskoran uji kemenarikan produk dapat dilihat pada Tabel 5.

Tabel 5. Penskoran pada angket uji kemenarikan dimodifikasi

\begin{tabular}{clcc}
\hline No & \multicolumn{1}{c}{ Pilihan jawaban } & $\begin{array}{c}\text { Skor } \\
(+)\end{array}$ & $\begin{array}{c}\text { Skor } \\
(-)\end{array}$ \\
1 & Sangat Setuju & 1 & 5 \\
2 & Setuju & 2 & 4 \\
3 & Netral (N) & 3 & 3 \\
4 & Tidak Setuju (TS) & 4 & 2 \\
5 & Sangat Tidak Setuju (STS) & 5 & 1 \\
\hline
\end{tabular}


Rumus menghitung persentase kepraktisan dan kemenarikan dengan rumus :

$\bar{P}=\frac{\sum_{i=1}^{n} \bar{P}_{i}}{n}$

Keterangan:

$\bar{P}=$ Skor rata-rata kemenarikan

$\bar{P}_{i}=$ Skor rata-rata kemenarikan peserta didik ke- $i$

$n$ = Banyaknya peserta didik

Selanjutnya rata-rata yang didapat dibandingkan dengan kriteria pengkategorian kemenarikan handout. Hasil yang diperoleh diintepretasikan dengan menggunakan Tabel 6.

\begin{tabular}{cc} 
Tabel. 6 & Kriteria \\
\multicolumn{2}{c}{ Pengkategorian } \\
Kemenarikan \\
\hline Interval Skor & Kategori \\
$0 \leq \bar{x}<1,8$ & Tidak menarik \\
$1.8 \leq \bar{x}<2,6$ & Kurang menarik \\
$2,6 \leq \bar{x}<3,4$ & Cukup menarik \\
$3,4 \leq \bar{x}<4,2$ & Menarik \\
$4,2 \leq \bar{x} \leq 5$ & Sangat menarik \\
\hline
\end{tabular}

\section{HASIL DAN PEMBAHASAN}

Hasil penelitian dan pengembangan ini adalah menghasilkan handout melalui pendekatan etnomatematika berbasis budaya lokal pada materi segi dan tiga segi empat. Tahapan yang digunakan dalam penelitian dan pengembangan ini menggunakan prosedur Borg and Gall yang dimodifikasi Sugiyono (Sugiyono, 2011). Tahapan yang digunakan direduksi menjadi tujuh langkah hingga ke tahap tujuh saja dari 10 tahap yang ada.

Pada tahap pertama masalah yang ada yaitu pemahaman peserta didik terhadap budaya lokal dan sudah digunakannya kurikulum 2013 Sedangkan masalahnya yaitu dilihat dari hasil UAS peserta didik pada semester sebelumnya yang belum mencapai KKM, serta bahan ajar yang digunakan dalam proses pembelajaran masih berupa buku cetak dan LKPD. Sehingga peneliti mencoba mengembangkan handout melalui pendekatan etnomatematika berbasis budaya lokal pada materi segi tiga dan segi empat. Pada kedua, penulis mengumpulkan beberapa bahan ajar, seperti buku, silabus, KI, KD, dan indikator pembelajaran sebagai sumber pembuatan produk.

Setelah potensi masalah dan informasi terkumpul selanjutnya, penulis tidak serta merta merubah isi materi yang ada, namun menggabungkan materi dari beberapa sumber, kemudian dirancang dengan memenuhi aspek syarat didaktis, aspek syarat konstuksi, aspek syarat teknis. Setelah analisis kebutuhan, maka selanjutnya tahap pembuatan produk berupa Handout melalui pendekatan etnomatematika berbasis budaya lokal pada materi segi tiga dan segi empat kelas VII pada materi segitiga dan segi empat. Handout menggunakan kertas B5, jenis huruf Times New Roman, dan menggunakan spasi 1,5 . Setelah desain produk selesai, kemudian dilakukan penilaian oleh para ahli materi, ahli bahasa, dan Ahli media. Dari masing masing penilaian yang diberikan oleh validator ahli, media pembelajaran yang dikembangkan dinyatakan valid dan layak digunakan sebagai media pembelajaran setelah dilakukan revisi. Untuk hasil validasi tahap akhir sebagai berikut.

\section{Tabel. 7 Hasil validasi oleh ahli materi

\begin{tabular}{ccc}
$\begin{array}{c}\text { Skor } \\
\text { Rata-rata }\end{array}$ & Kategori & Keterangan \\
3,8 & Valid & Tidak Revisi \\
\hline
\end{tabular}

Tabel. 8 Hasil validasi oleh ahli bahasa

\begin{tabular}{ccc}
\hline $\begin{array}{c}\text { Skor } \\
\text { Rata-rata }\end{array}$ & Kategori & Keterangan \\
3,93 & Valid & Tidak Revisi \\
\hline
\end{tabular}

Tabel. 9 Hasil validasi oleh ahli media

\begin{tabular}{ccc}
$\begin{array}{c}\text { Skor } \\
\text { Rata-rata }\end{array}$ & Kategori & Keterangan \\
3,81 & Valid & Tidak Revisi \\
\hline
\end{tabular}


Desimal, 1 (1), 2018 - 77

Elma Purnama Aini, Komarudin, Ruhban Masykur

Tabel 10. Hasil Respon

\begin{tabular}{cccc}
\hline Resp. & $\begin{array}{c}\text { Jumlah } \\
\text { Skor }\end{array}$ & $\begin{array}{c}\text { Skor } \\
\text { kelayakan }\end{array}$ & Kategori \\
1 & 76 & 3,8 & $\mathrm{P}$ \\
2 & 72 & 3,6 & $\mathrm{P}$ \\
3 & 70 & 3,5 & $\mathrm{P}$ \\
4 & 78 & 3,9 & $\mathrm{P}$ \\
5 & 73 & 3,65 & $\mathrm{P}$ \\
6 & 68 & 3,4 & $\mathrm{P}$ \\
7 & 78 & 3,9 & $\mathrm{P}$ \\
8 & 78 & 3,15 & $\mathrm{CP}$ \\
9 & 84 & 4,2 & $\mathrm{SP}$ \\
jumlah & 689 & 3,8 & PRAKTIS \\
& & & \\
\hline
\end{tabular}

Setelah mendapat Saran dan masukan dari validator ditabulasi dan dilaksanakan agar perangkat pembelajaran dapat diimplementasikan. Uji Coba Produk dilakukan dalam 2 tahapan yaitu uji coba terbatas dengan melibatkan 9 peserta didik dan uji coba luas yang terdiri dari 29 peserta didik. Pada tahapan uji coba terbatas didapat hasil respon peserta didik bahwa produk layak digunakan.

Dari pengujian data yang ditampilkan dalam Tabel 10, tingkat kepraktisan produk pada uji coba terbatas memperoleh skor rata-rata 3,8 dengan kriteria "Praktis" dan uji coba luas mencapai skor rata-rata 4,02 dengan kriteria "Menarik". Dalam hal ini peneliti menyimpulkan bahwa ada produk dinyatakan praktis dan menarik. Berdasarkan angket respon peserta didik pada uji kepraktisan dan kemenarikan produk ini sudah dinyatakan praktis dan sangat menarik sehingga tidak dilakukan perbaikan.

Penelitian ini sama dengan hasil penelitian sebelumnya diantaranya oleh Efendi dkk yang mengungkakan bahwa siswa lebih tertarik belajar menggunakan bahan ajar Handout (Efendi, 2012; Yana, 2014). Selain itu peneliti lain mengungkapkan bahwa pengembangan Handout mendapatkan respon yang layak oleh para ahli media dan disarankan agar segera mengujicobakan bahan ajar tersebut (Helmanda, 2012).

\section{SIMPULAN DAN SARAN}

Berdasarkan hasil penelitian yang sudah dibahas maka dapat disimpulkan bahwa penelitian ini menghasilkan sebuah bahan ajar berupa Handout dengan pendekatan Etnomatematika dalam pembelajaran matematika yang telah dikembangkan melalui prosedur 7 Langkah dari 10 langkah Borg and Gall. Ditinjau dari Kualitas handout yang telah dikembangkan dari aspek kevalidan, memperoleh skor rata-rata 3,97 dari semua para ahli dengan kategori valid. Ditinjau dari aspek kepraktisan, didasarkan dari hasil angket respon peserta didik dengan skor rata-rata 3,67 dengan kategori praktis. Ditinjau dari aspek kemenarikan, didasarkan dari ratarata angket respon peserta didik memperoleh nilai 4,02 dengan kategori menarik. Semua ini menyatakan bahwa bahan ajar Handout yang telah dikembangkan valid (layak) dan sangat menarik untuk digunakan dalam pembelajaran matematika

Berdasarkan kesimpulan penulis menyarankan bahwa guru-guru disekolah sebaiknya menggunakan bahan ajar berupa Handout dalam rangka meningkatkan pemahaman peserta didik. Selain itu peneliti selanjutnya direkomendadsikan agar dikembangkan pada materi yang lebih luas.

\section{DAFTAR PUSTAKA}

Anggoro, B. S. (2016). Meningkatkan Kemampuan Generalisasi Matematis Melalui Discovery Learning dan Model Pembelajaran Peer Led Guided Inquiry. Al-Jabar: Jurnal Pendidikan Matematika, 7(1), 11-20. https://doi.org/10.24042/ajpm.v7i1. 23

Astri, W., Aji, A., Tias, W., \& Budiman, S. (2013). Peran Etnomatematika dalam Membangun Karakter Bangsa. In Prosiding Seminar Nasional 
Matematika dan Pendidikan Matematika. Jurusan Pendidikan Matematika FMIPA UNY.

Avval, F. Z., Jarahi, L., Ghazvini, K., \& Youssefi, M. (2013). Distribution of Handouts in Undergraduate Class to Create More Effective Educational Environment. Int J Ed Res, 12(1), 1-6. Cahyono, A. E. Y. (2017). Pengembangan perangkat pembelajaran dengan model PBL berorientasi pada kemampuan berpikir kreatif dan inisiatif siswa. Pythagoras: Jurnal Pendidikan Matematika, 12(1), 1-11.

Efendi, S. L. (2012). Pengembangan Handout Berbasis Kontekstual Untuk Pembelajaran Koloid Sebagai Sumber Belajar Mandiri Peserta Didik Kelas XI SMA/MA. Skripsi. Yogyakarta: Program Studi Pendidikan Kimia Jurusan Pendidikan Kimia Fakultas Matematika Dan Ilmu Pengetahuan Alam Universitas Negeri Yogyakarta.

Faizah, A. N., \& Eko Setyadi, K. (n.d.). Nurhidayati, 2014, Pengembangan Handout Fisika Berbasis Guided Note Taking Guna Meningkatkan Motivasi Belajar Siswa Kelas X di SMA N 3 Purworejo Tahun Ajaran 2013/2014. Jurnal Radiasi, 5(2).

Helmanda, R. (2012). Pengembangan Handout Matematika Berbasis Pendekatan Realistik Untuk Siswa SMP Kelas VII Semester 2. Jurnal Pendidikan Matematika, 1(1).

Irwandani, I., \& Juariyah, S. (2016). Pengembangan Media Pembelajaran Berupa Komik Fisika Berbantuan Sosial Media Instagram sebagai Alternatif Pembelajaran. Jurnal Ilmiah Pendidikan Fisika Al-Biruni, 5(1), 33. https://doi.org/10.24042/jpifalbiru ni.v5i1.103

Nelson-Wong, E., \& Callaghan, J. P. (2014). Transient low back pain development during standing predicts future clinical low back pain in previously asymptomatic individuals. Spine, 39(6), E379-E383.

Putra, M. I. S. (2016). Efektivitas Pembelajaran Statistik dengan Pendekatan Keterampilan Multi Representasi untuk Meningkatkan Hasil Belajar Mahasiswa PGMI UNIPDU Jombang. JMPM: Jurnal Matematika Dan Pendidikan Matematika, 1(1), 65-75.

Rahmayani, F., Hindun, I., \& Hudha, A. M. (2015). Pengembangan Handout Berbasis Kontekstual Pada Pelajaran Biologi Materi Bioteknologi Untuk Siswa Kelas XII SMK Negeri 02 Batu. Jurnal Pendidikan Biologi Indonesia, 1(1).

Sugiyono. (2011). Metode Penelitian Kuantitatif Kualitatif dan R\&D. Bandung: Alfabeta.

Syaban, M.

(2008). Menumbuhkembangkan Daya Matematis Siswa. Educare, 5(2).

Wahyuni, A., Tias, A. A. W., \& Sani, B. (2013). Peran etnomatematika dalam membangun karakter bangsa. In Makalah Seminar Nasional Matematika dan Pendidikan Matematika, Prosiding, Jurusan Pendidikan Matematika FMIPA UNY, Yogyakarta: UNY.

Widyastuti, R. (2015). Proses Berpikir Siswa dalam Menyelesaikan Masalah Matematika berdasarkan Teori Polya ditinjau dari Adversity Quotient Tipe Climber. Al-Jabar: Jurnal Pendidikan Matematika, 6(2), 183-194.

Widyawati, S. (2016). Pengaruh Kemampuan Koneksi Matematis Siswa terhadap Prestasi Belajar Matematika Ditinjau dari Gaya Belajar pada Materi Bangun Ruang Sisi Datar Siswa Kelas IX SMP di Kota Metro. Iqra': Jurnal Kajian Ilmu Pendidikan, 1(1), 47-68.

Yana, A. S. (2014). Pengembangan Handout Berbasis Model Sains Teknologi Masyarakat pada Materi Wujud Zat dan Perubahan Zat untuk Pembelajaran IPA Fisika SMP Kelas 
Desimal, 1 (1), 2018 - 79

Elma Purnama Aini, Komarudin, Ruhban Masykur

VII Semester 1. Pillar of Physics

Education, 3(1). 